\title{
Oven Solar Dryer Teknologi sebagai Upaya Peningkatan Produksi Ikan Asin pada Masyarakat Nelayan di Gampong Deah Raya Kota Banda Aceh
}

\section{Solar Dryer Oven Technology as an Effort to Increase Salted Fish Production in the Fishing Communities in Deah Raya Village, Banda Aceh City}

\author{
${ }^{1}$ Herlina, ${ }^{2}$ Dian Aswita, ${ }^{3}$ Ikramullah Zein \\ ${ }^{1}$ Pendidikan Ekonomi, FKIP, Universitas Serambi Mekkah, Aceh \\ 2 Pendidikan Biologi, FKIP, Universitas Serambi Mekkah, Aceh \\ ${ }^{3}$ Teknik Industri, FT, Universitas Serambi Mekkah, Aceh \\ Korespondensi: Herlina, lalutaflower@gmail.com
}

\begin{abstract}
Salted fish processing is one of the traditional ways of preserving fish carried out by the community when the fish harvest is so abundant, so that it can reduce the impact of losses due to fish spoilage. Implementation of community service is intended to introduce oven solar dryer technology as a simple technology to help realize increased productivity of salted fish processing. The target of PKM implementation consists of two groups, the engkut taleung group and the asen belideung group, in Gampong Deah Raya, Syiah Kuala District, Banda Aceh. The method used in this PKM is a technology transfer method. PKM provides a solution by utilizing technology as an effort to increase the production of hygienic salted fish production in the coastal area of Banda Aceh. The result of this PKM activity is the success in the manufacture and assembly of solar dryer ovens, so that PKM activities can be carried out. Technical training on the use of ovens can run well, marked by an increase in community knowledge and skills in using ovens for drying and making salted fish. Furthermore, the solar dryer oven unit is handed over to the community as a salted fish processing technology that can be the best solution in reducing fish spoilage and damage, and can overcome excess catches that have not been marketed, and produce more hygienic salted fish production.
\end{abstract}

Keywords: fishing communities, oven solar dryer, salted fish, technology.

\begin{abstract}
Abstrak. Pengolahan ikan asin merupakan salah satu cara pengawetan ikan secara tradisional yang dilakukan oleh masyarakat pada saat hasil panen ikan yang begitu melimpah, sehingga dapat mengurangi dampak kerugian akibat pembusukan ikan. Pelaksanaan pengabdian kepada masyarakat ini dimaksudkan untuk memperkenalkam oven solar dryer teknologi sebagai teknologi sederhana guna membantu mewujudkan peningkatan produktivitas pengolahan ikan asin. Sasaran pelaksanaan PKM terdiri dari dua kelompok, kelompok usaha engkut taleung dan kelompok usaha asen belideung, di Gampong Deah Raya, Kecamatan Syiah Kuala, Banda Aceh. Metode yang digunakan dalam PKM ini adalah metode alih teknologi. PKM ini memberikan solusi dengan memanfaatkan teknologi berupa oven solar dryer sebagai upaya peningkatan hasil produksi ikan asin yang higienis di wilayah pesisir kota Banda Aceh. Hasil kegiatan PKM ini adalah keberhasilan dalam pembuatan dan perakitan oven solar dryer, sehingga kegiatan PKM dapat terlaksana. Pelatihan teknis penggunaan oven dapat berjalan dengan baik, ditandai dengan adanya peningkatan pengetahuan dan keterampilan masyarakat dalam menggunakan oven untuk melakukan pengeringan dan pembuatan ikan asin. Selanjutnya, unit oven solar dryer tersebut diserahkan kepada masyarakat sebagai teknologi pengolahan ikan asin yang dapat menjadi solusi terbaik dalam mengurangi pembusukan dan kerusakan ikan, serta dapat
\end{abstract}


mengatasi kelebihan hasil tangkapan yang belum laku di pasarkan, dan menghasilkan produksi ikan asin yang lebih higienis.

Kata Kunci: masyarakat nelayan, oven solar dryer, ikan asin, teknologi.

\section{Pendahuluan}

Pengolahan ikan asin merupakan salah satu cara pengawetan ikan secara tradisional yang dilakukan oleh masyarakat pada saat hasil panen ikan yang begitu melimpah, sehingga dapat mengurangi dampak kerugian akibat pembusukan ikan. Pengolahan ikan asin secara tradisional melalui metode penggaraman telah dilakukan secara turun-temurun, dan dapat kita temukan di kalangan masyarakat nelayan di Aceh. Afrianto \& Liviawaty (1994) menyebutkan bahwa proses penggaraman dimulai ketika garam yang berpenetrasi ke daging ikan menyebabkan cairan keluar dari daging ikan, kemudian cairan tersebut mengencerkan garam menjadi larutan dan partikel garam tersebut masuk ke daging ikan.

Usaha ikan asin dapat memberikan keuntungan bagi pelaku usaha, sesuai dengan hasil penelitian Situmeang \& Hendrik (2017) yang mengungkapkan bahwa keuntungan pembuatan ikan asin sebesar Rp 9.895.083,- dari total investasi Rp 76.952.000,-. Pengembangan usaha ikan asin berpotensi untuk mencapai kesejahteraan bagi masyarakat karena dapat memberi dampak positif bagi semua pihak antara lain: 1) bagi si pedagang ikan asin bila penjualan meningkat, maka akan terjadi peningkatan pendapatan, 2) bagi para nelayan yang tidak merangkap sebagai pedagang ikan asin juga akan memperoleh keuntungan karena ikan yang kurang laku di pasar tetap dibeli oleh pedagang ikan asin sebab untuk jenis ikan tertentu memang dipisahkan dari ikan-ikan yang dijual di pasar, 3) bagi masyarakat akan tersedia keanekaragaman pangan.

Seiring perkembangan ilmu dan teknologi, serta peningkatan kualitas hidup masyarakat, pemanfaatan teknologi pun dilakukan dalam mengatasi masalahmasalah yang dihadapi dalam kehidupan sehari-hari. Salah satunya adalah pada bidang ekonomi, dengan upaya untuk meningkatkan keuntungan finansial dan pendapatan bagi masyarakat nelayan khususnya pada pengolahan ikan asin. Penggunaan teknologi sederhana dalam pengelohan ikan asin pun dimaksudkan untuk meningkatkan produksi ikan asin, sehingga dapat meningkatan perekonomian masyarakat. Hal ini sejalan dengan visi kota Banda Aceh sebagai Kota Madani, dengan salah satu misinya untuk memperkuat ekonomi kerakyatan. Dasar ini yang kemudian menjadi alasan pelaksanaan pengabdian kepada masyarakat dengan memanfaatkan teknologi sederhana guna membantu mewujudkan peningkatan produktivitas pengolahan ikan asin.

Oven solar dryer merupakan alat pengering yang didesain dengan menyerap dan memanfaatkan energi tenaga surya, sehingga efek yang ditimbulkan seperti efek rumah kaca yang dapat menyimpan panas meskipun terdapat perubahan cuaca dan iklim. Oven ini memiliki proyektor yang berfungsi menyalurkan panas secara merata di dalamnya, dan memiliki kipas yang berfungsi mengatur suhu. Oven solar dryer merupakan teknologi yang digunakan pada pelaksanaan pengabdian kepada masyarakat nelayan yang sekaligus merangkap menjadi pengusaha ikan asin di Banda Aceh.

Pemanfaatan teknologi oven solar dryer memberikan dampak positif pada berbagai bidang industri, baik skala mikro maupun skala makro. Penggunaan yang mudah, dengan biaya produksi yang lebih rendah (Deosthale $\&$ Kewat, 2018), serta dapat dimanfaatkan untuk berbagai bahan yang akan dikeringkan, menjadikannya alternative yang dapat dikembangkan. Chavda \& Kumar (2009), menyebutkan bahwa potensi solar dryer hadir pada berbagai segmen agroindustri karena kualitas yang lebih baik dari produk agro yang bernilai tinggi, kebersihan yang lebih baik dan juga periode pengembalian yang lebih rendah. Selain itu, Mwamba, et al. (2017) melakukan studi terhadap pengeringan buah mangga menggunakan solar 
dryer dan oven biasa menemukan bahwa pengeringan solar dryer pada mangga memiliki efek menguntungkan bagi kesehatan manusia. Hal yang sama juga disebutkan oleh Sanmartin, et al. (2017), dengan studinya pada berbagai produk pertanian mengggunakan solar dryer.

Bukan hanya pada produk pertanian, Hubackova, et al., (2014) menyebutkan bahwa solar dryer diteliti sebagai salah satu teknik perspektif untuk pengolahan ikan di Kamboja. Berdasarkan uraian tersebut diketahui bahwa teknologi oven solar dryer ini dapat ditransfer kepada masyarakat dalam berbagai bidang (pertanian, perkebunan, dan perikanan) untuk mengurangi kerugian pasca panen dan meningkatkan pendapatan perekonomian mereka.

Adapun keunggulan pengolahan ikan asin dengan menggunakan oven solar dryer adalah:

1. Mengatasi kelemahan penjemuran secara tradsional yaitu ketika hujan turun tiba-tiba sehingga menyebabkan kelembaban pada ikan meningkat.

2. Menghasilkan ikan asin yang lebih higienis, bebas dari debu, dan bebas dari hinggapnya lalat yang akan menghasilkan telur, sebagai penyebab berulatnya ikan asin dan menjadi busuk serta terbuang.

3. Mengatasi proses penyimpanan, dimana sebagian pedagang memang melakukan penyimpanan di kulkas, yang sifatnya terbatas dan pada akhirnya mempengaruhi perubahan aroma dan rasa pada produk setelah diproses/ dijemur ulang.

Berdasarkan observasi awal, diketahui bahwa terdapat penurunan dalam produksi ikan asin pada musim penghujan, sering sekali ikan asin gagal kering dengan sempurna sehingga menyebabkan munculnya belatung dan pembusukan ikan. Hal ini juga mempengaruhi proses jual beli. Umumnya masyarakat lebih tertarik dengan bentuk tampilan ikan asin yang bagus, bersih, higienis, dan tentunya dengan rasa yang enak. Akibatnya, penurunan stok ikan asin pada musim penghujan menyebabkan harga jual tinggi dan daya beli masyarakat menjadi menurun. Selain itu, teknologi ini juga dapat digunakan dalam mengatasi hasil panen ikan yang begitu melimpah, untuk kemudian diolah menjadi ikan asin yang higienis dengan jumlah yang besar (daya tampung hingga $15 \mathrm{~kg}$ ). Tak hanya itu, kedua kelopok mitra sehari-harinya diketahui melakukan pengolahan ikan asin secara tradisional dengan metode penggaraman dan penjemuran langsung di bawah matahari. PKM ini memberikan solusi dengan memanfaatkan teknologi berupa oven solar dryer sebagai upaya peningkatan hasil produksi ikan asin yang higienis di wilayah pesisir sehingga berdampak pada peningkatan keuntungan finansial dan pendapatan bagi pengusaha ikan asin.

\section{Metode Pelaksanaan}

Tempat dan Waktu. Kegiatan PKM dilaksanakan di Gampong Deah Raya, Kecamatan Syiah Kuala, Banda Aceh mulai dari Mei-Oktober 2018. Tempat kegiatan PKM berjarak 8,8 km dari Universitas Serambi Mekkah.

Khalayak Sasaran. Sasaran pelaksanaan PKM terdiri dari dua kelompok, yaitu kelompok pertama adalah kelompok Usaha Engkut Taleung yang diketuai Bapak Darwin berada di Dusun Tengku Chik Musa, dan kelompok kedua adalah kelompok Usaha Asen Belideung yang diketuai Ibu Arinah berada di Dusun Nek Bayan.

Metode Pengabdian. Metode yang digunakan dalam PKM ini adalah metode alih teknologi (Dewi \& Widiyawati, 2019; Mudzanatun, Fajriyah, \& Muflihati, 2019) yang dimulai dengan: melakukan observasi sebelum memulai pengabdian, melakukan komunikasi dengan kedua kelompok mitra, pembuatan oven solar dryer, memberikan pelatihan teknis penggunaan oven, dan penyerahan oven solar dryer kepada masyarakat kelompok usaha ikan asin. Selanjutnya juga dilakukan proses 
bimbingan dan pendampingan teknis agar terdapat keberlanjutan dalam produksi pengolahan ikan asin.

Indikator Keberhasilan. Keberhasilan kegiatan PKM dapat dilihat dari indikator capaian program kemitraan masyarakat di Gampong Deah Raya sebagai berikut:

1. Terlaksananya program kemitraan masyarakat di Gampong Deah Raya pada dua kelompok yaitu kelompok Usaha Engkut Taleung dan kelompok Usaha Asen Belideung.

2. Terselesikannya pembuatan oven solar dryer sehingga dapat digunakan pada saat pelatihan teknis dan untuk diserahkan kepada masyarakat.

3. Adanya peningkatan pengetahuan dan keterampilan komunitas masyarakat nelayan dalam menggunakan oven solar dryer untuk pengolahan ikan asin. Evaluasi ketrampilan dilakukan pada saat pelatihan teknis penggunaan oven secara langsung. Peserta PKM diminta memperhatikan dan menirukan proses penggunaan oven dalam pengolahan ikan asin. Peserta yang mampu melakukan proses pengolahan ikan asin dengan menggunakan oven secara tepat sehingga menghasilkan ikan asin yang higienis dengan jumlah yang juga mengalami peningkatan, dianggap telah memiliki pengetahuan dan keterampilan yang baik.

4. Penyerahan unit oven solar dryer kepada masyarakat.

Metode Evaluasi. Proses evaluasi pada kegiatan PKM ini difokuskan pada ketercapaian pembuatan oven sehingga dapat digunakan untuk memproduksi ikan asin dan penilaian keterampilan penggunaan oven oleh masyarakat dimulai sejak menyiapkan ikan, penjemuran dan proses panen ikan asin.

\section{Hasil dan Pembahasan}

Pengabdian kepada masyarakat yang telah dikukan di Gampong Deah Raya, Kecamatan Syiah Kuala, Banda Aceh dalam menggunakan teknologi sederhana dalam pengolahan ikan asin yang higienis dalam jumlah banyak. Kegiatan ini dilaksanakan terhadap kelompok nelayan yang sekaligus merupakan kelompok pengusaha ikan asin di gampong tersebut. Hasil yang telah dicapai pada Program Kemitraan Masyrakat (PKM) dijabarkan sebagai berikut.

\section{A. Observasi}

Observasi dilakukan beberapa tahap, yaitu dimulai dengan melakukan pendekatan dan pengenalan kepada masyarakat nelayan dan pengusaha ikan asin mengenai kegiatan PKM ini, khususnya pada masalah-masalah yang mereka alami pada saat produksi dan pengolahan ikan segar menjadi ikan asin, seperti penurunan jumlah produksi ikan asin pada musim penghujan, karena ikan gagal terjemur sehingga munculnya belatung dan ikan menjadi busuk (Gambar 1). Selain itu, mengatasi hasil panen ikan yang begitu melimpah, yang tidak habis terjual sehingga menjadi tersisa dan dapat membusuk. Tahap selanjutnya adalah menginformasikan kepada mereka mengenai proses pembuatan dan perakitan oven di Gampong Deah Raya sebagai solusi yang ditawarkan untuk mengatasi permasalahan tersebut.

\section{B. Komunikasi dengan Kedua Kelompok Sasaran}

Tim pelaksana PKM selanjutnya mengkomunikasikan segala sesuatu yang berkaitan dengan pelaksanaan PKM di Gampong Deah Raya, dengan melibatkan dua kelompok masyarakat yaitu kelompok pengusaha ikan asin. Pada tahap ini, tim pelaksana juga meminta kesedian mereka untuk menjadi peserta dan terpilihlah dua kelompok, yaitu kelompok usaha engkut taleung yang diketuai Bapak Darwin dan kelompok usaha asen belideung yang diketuai Ibu Arinah. Selanjutnya dimulai dengan penyiapan alat dan bahan yang akan digunakan saat pembuatan dan perakitan oven, dan menentukan siapa saja yang terlibat pada proses pembuatan oven. 


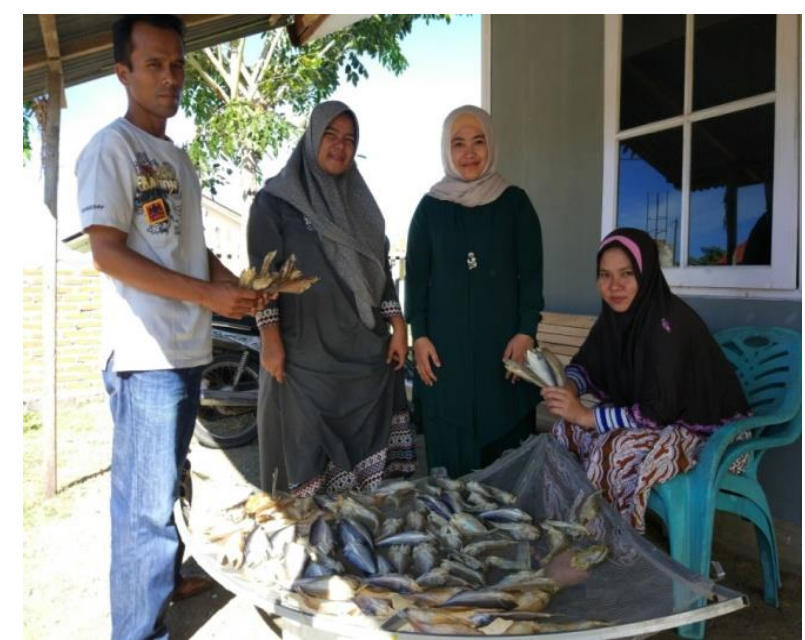

a

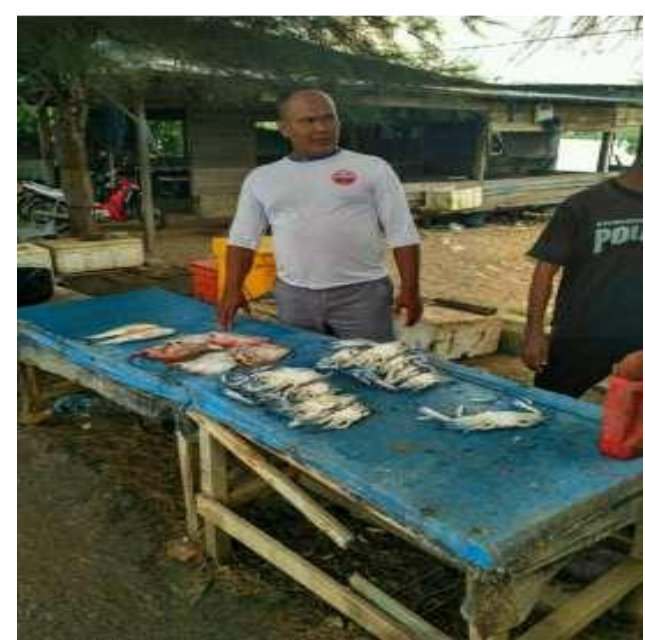

$\mathrm{b}$

Gambar 1. Tahap Observasi Lapangan (a. usaha asen belideung Ibu Arinah; b. usaha engkut taleung Bapak Darwin)

\section{Pembuatan Oven Solar Dryer}

Pembuatan oven dilakukan di rumah Ibu Arinah di Dusun Nek Bayan. Pembuatan oven dilakukan oleh tim, Bpk. Sriwijaya yang merupakan tenaga ahli dari Lembaga Pendidikan Teknologi Terapan Indonesi (LPTTI) dan tenaga terampil lainnya (tukang). Ide pembuatan oven ini bersumber pada kajian Bintang, Pongoh, \& Onibala pada tahun 2013, dan juga kajian Hanafri, Emawan, Kustanti, \& Rahayu pada tahun 2009 (Gambar 2).
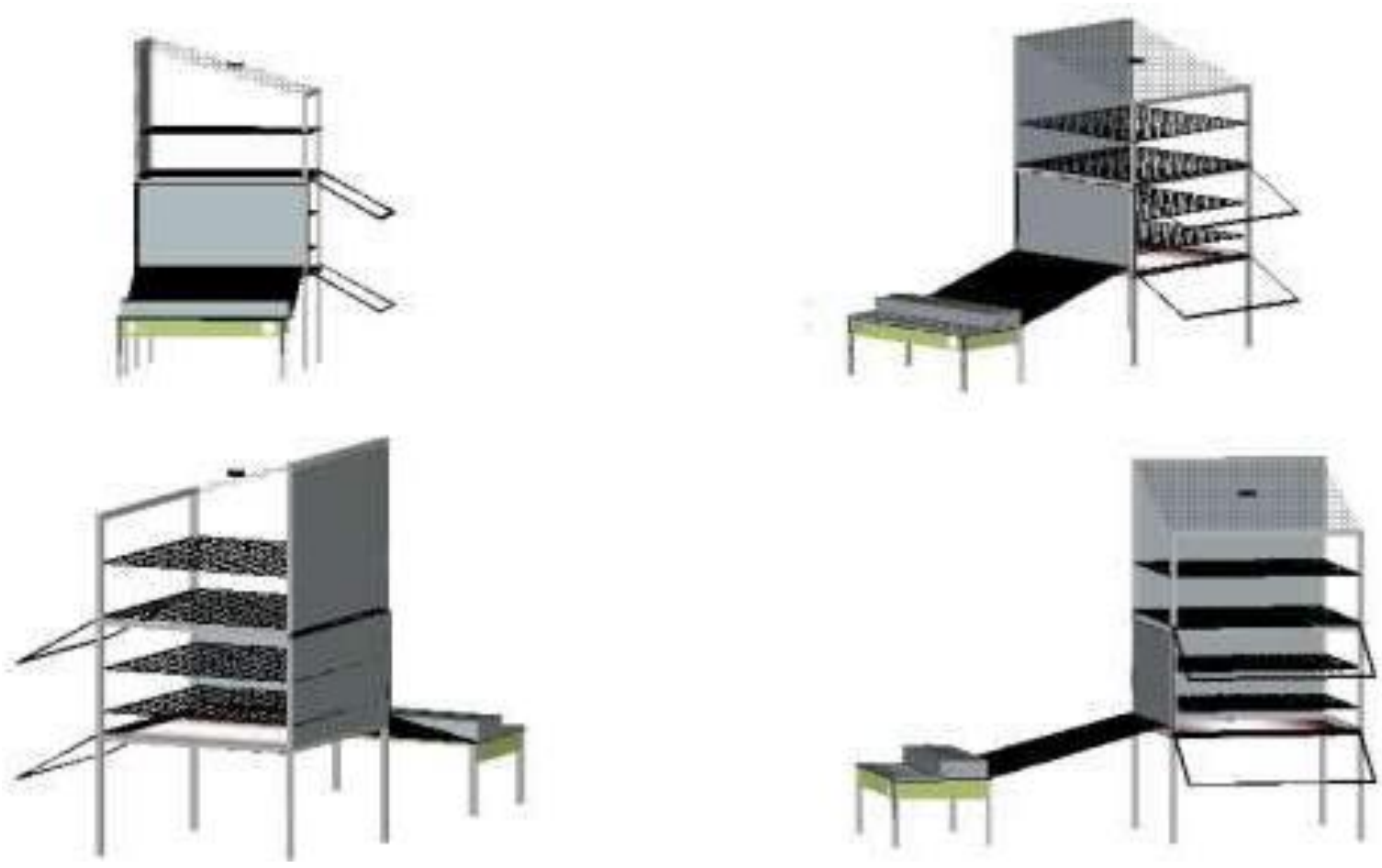

Gambar 2. Konstruksi Oven Solar Dryer (Sriwijaya, 2018)

Adapun bahan-bahan yang digunakan untuk perakitan oven solar dryer dengan volume $100 \mathrm{~cm}$ × $200 \mathrm{~cm}$ x $180 \mathrm{~cm}$ pada program pengabdian kepada masyarakat ini, diantaranya adalah sebagai berikut.

1. Aluminium 3.5" tiang utama dryer,

2. Aluminium $0.5^{\prime \prime} \times 1$ penyangga rak, 
3. Aluminium list,

4. Magnet pintu dan handle,

5. Engsel piano,

6. Paku rivet,

7. Paku sekrup 0.25",

8. Sillicon esealant,

9. Kawat ram untuk 4 rak,

10. Seng plat Galvalum $0.25 \mathrm{~mm}$,

11. Kolektor solar dan penyalur,

12. Kipas pendorong 12VDC (opsional),

13. Kaca dengan ketebalan $\pm 5 \mathrm{~mm}$.

Selain itu, peralatan penunjang yang diperlukan untuk pembuatan oven solar dryer antara lain: gergaji besi, mesin potong alumunium, bor listrik, mata bor beton, mata bor listrik, obeng, cuter, tang, rivet, meteran, alat siku 45, kikis dan amplas. Adapun konstruksi oven solar dryer rakitan ditampilkan pada gambar berikut.

Adapun langkah-langkah pembuatan oven solar dryer adalah sebagai berikut (Gambar 3).

1. Persiapan bahan-bahan dan peralatan yang akan dipakai,

2. Melakukan pemotongan bahan berdasarkan ukuran yang telah ditetapkan,

3. Membuat kerangka oven sesuai rancangan,

4. Pemasangan rangka alat pengering yang diawali dengan merangkai kaki dan rak-I, kemudian rak-II dan seterusnya sampai rak-IV. Sebelum rak-II digabungkan dengan rak-I maka terlebih dahulu memasukkan plastik acrylic pada bagian kiri, kanan dan bagian belakang, kecuali bagian depan yang disebut pintu,

5. Merangkai bagian penutup dari alat pengering,

6. Pengujian alat dengan cara mengeringkan ikan.
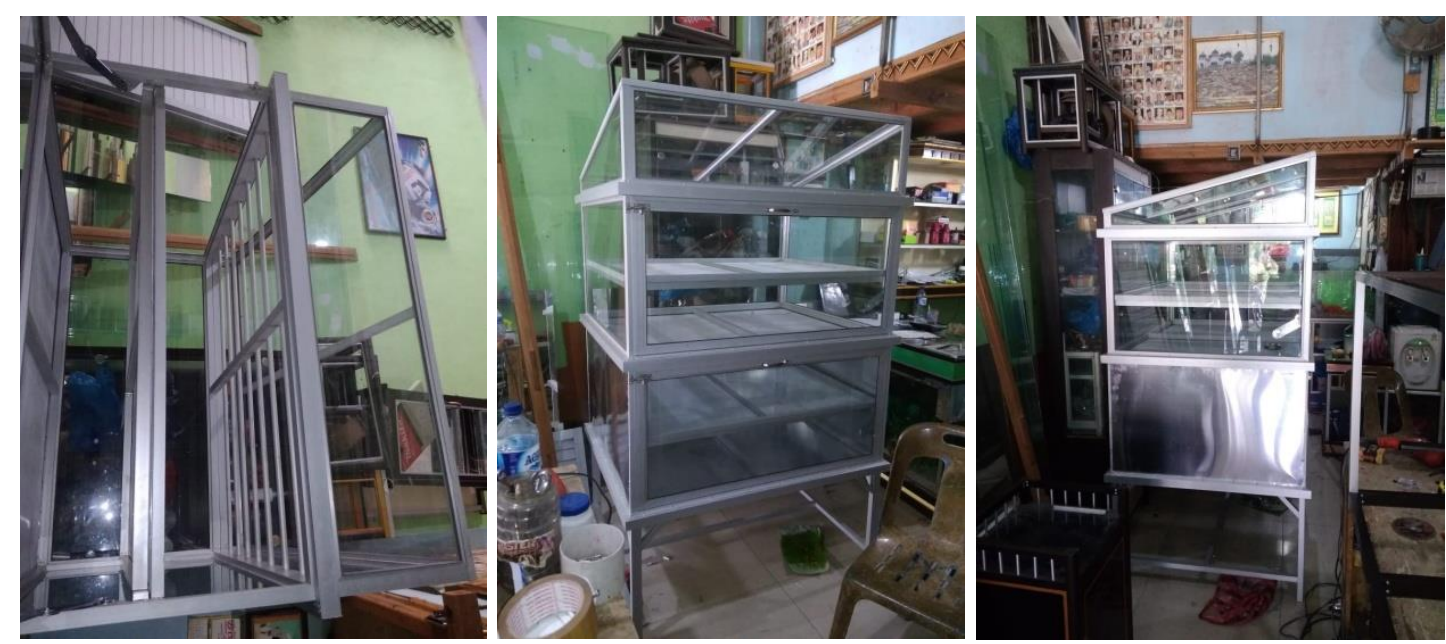

Gambar 3. Perakitan dan Pembuatan Oven Solar Dryer

Spesifikasi oven yang dikembangkan dapat memberikan manfaat bagi kelompok usaha ikan asin adalah sebagai berikut: bahan yang digunakan anti karat (karena alumunium dengan kualitas yang baik, sehingga bila terkena hujan dan panas masih dapat bertahan lama) dan cocok untuk wilayah pesisir. Selain itu, suhu panas terjaga maksimum hingga 75-80 derajat saat puncak panas matahari. Oven ini juga dapat dibongkar pasang, sehingga memberi kemudahan ketika akan dipindahkan ke lokasi lain tanpa mengalami kerusakan. Selanjutnya, ukuran muatan yang lebih besar sehingga dapat menampung sekitar $15 \mathrm{~kg}$ ikan, sehingga dapat meningkatkan jumlah produksi dari jumlah biasanya (Gambar 4). 

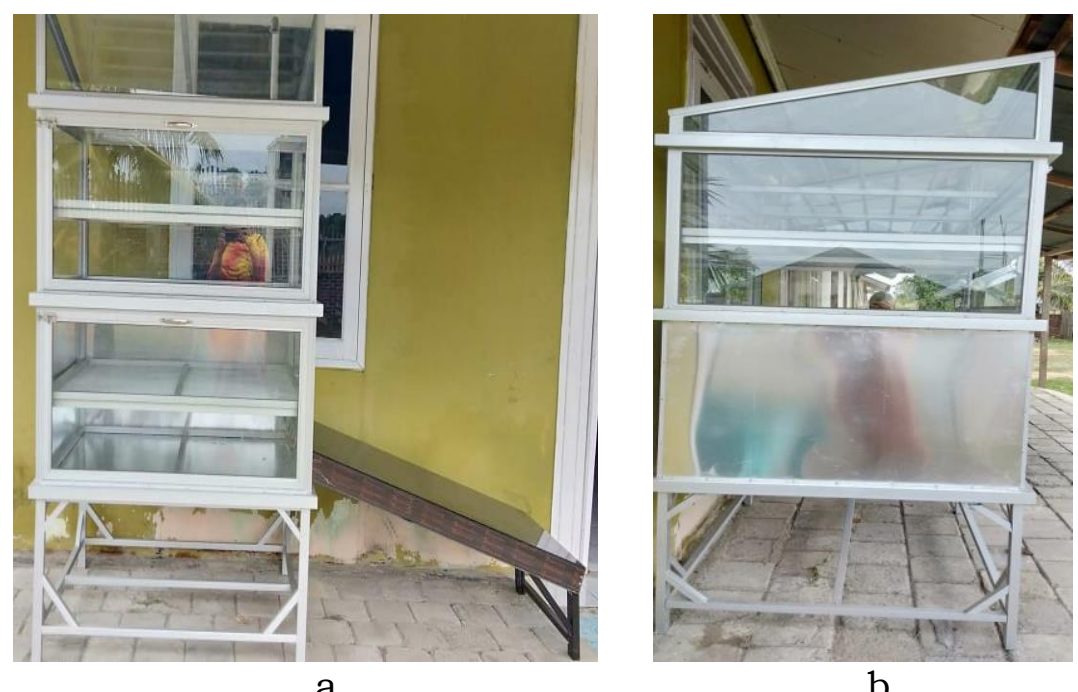

Gambar 4. Oven Solar Dryer (a. tampak depan; b. tampak samping)

\section{Pelatihan Teknis Penggunaan Oven}

Pelatihan penggunaan oven dilakukan di kedua dusun di Gampong Deah Raya, yaitu dusun Tengku Chik Musa dan dusun Nek Bayan. Pelatihan dilaksanakan setelah pembuatan oven solar dryer selesai dilakukan, dengan cara memberi penyuluhan dan mendemonstrasikan bagaimana penggunaan serta pengoperasian alat hingga mampu menghasilkan ikan asin. Materi yang disampaikan adalah tentang manfaat dari oven solar dryer bagi peningkatan produksi ikan asin seta bagaimana menggunakan oven solar dryer tersebut. Pelatihan diarahkan langsung oleh tim, dengan metode demonstrasi dan diskusi serta dilanjutkan dengan praktek langsung oleh peserta (Gambar 5).

Pemberian penyuluhan dimaksudkan sebagai sharing informasi dan pengetahuan mengenai oven solar dryer sebelum digunakan sehingga masyarakat mengerti untuk apa alat tersebut dirakit, bagaimana keuntungan yang akan diperoleh dari hasil pengeringan menggunakan oven solar dryer, serta dampak positif yang diharapkan yaitu peningkatan produksi ikan asin yang pada akhirnya akan meningkatkan daya jual mereka sehingga perekonomian juga dapat ditingkatkan. Kegiatan penyuluhan ini dilakukan secara oral dan menggunakan metode diskusi dan tanya jawab.

Kegiatan demonstrasi dilakukan untuk mengenalkan oven solar dryer dan cara penggunaannya. Praktek langsung juga dilakukan oleh masyarakat saat pelatihan ini berlangsung. Hal ini dimaksudkan untuk memudahkan adanya sharing keterampilan antara tim pelaksana PKM dengan masyarakat setempat.

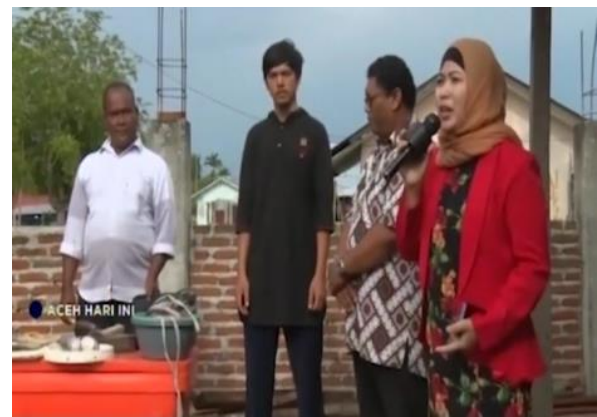

a

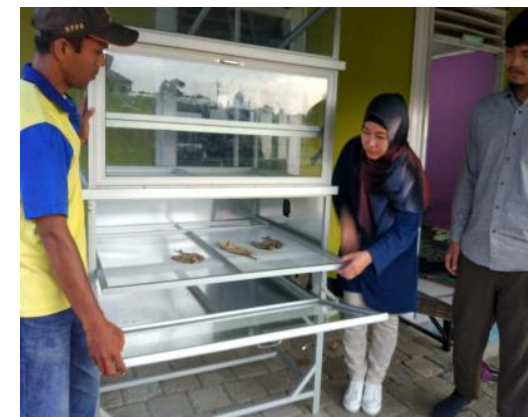

$\mathrm{b}$

Gambar 5. Pelatihan Teknis Penggunaan Oven (a. penyuluhan; b. demontrasi penggunaan oven solar dryer) 


\section{E. Penyerahan Oven Solar Dryer}

Penyerahan oven solar dryer diberikan kepada kedua kelompok peserta yang terlibat pada proses pelaksanaan PKM ini setelah proses pelatihan selesai dilakukan. Selain itu, dilakukan juga proses pendampingan kepada peserta untuk menentukan keberlanjutan dari program ini. Kegiatan ini diharapkan melatih kemandirian mereka dalam penggunaan teknologi untuk pengolahan ikan asin, sebagaimana kemandirian yang telah mereka miliki sebelumnya saat melakukan pengolahan ikan asin dengan metode tradisional yaitu melalui proses penggaraman dan penjemuran di bawah matahari. Dokumentasi pendampingan dan penyerahan oven dapat dilihat pada Gambar 6. berikut.
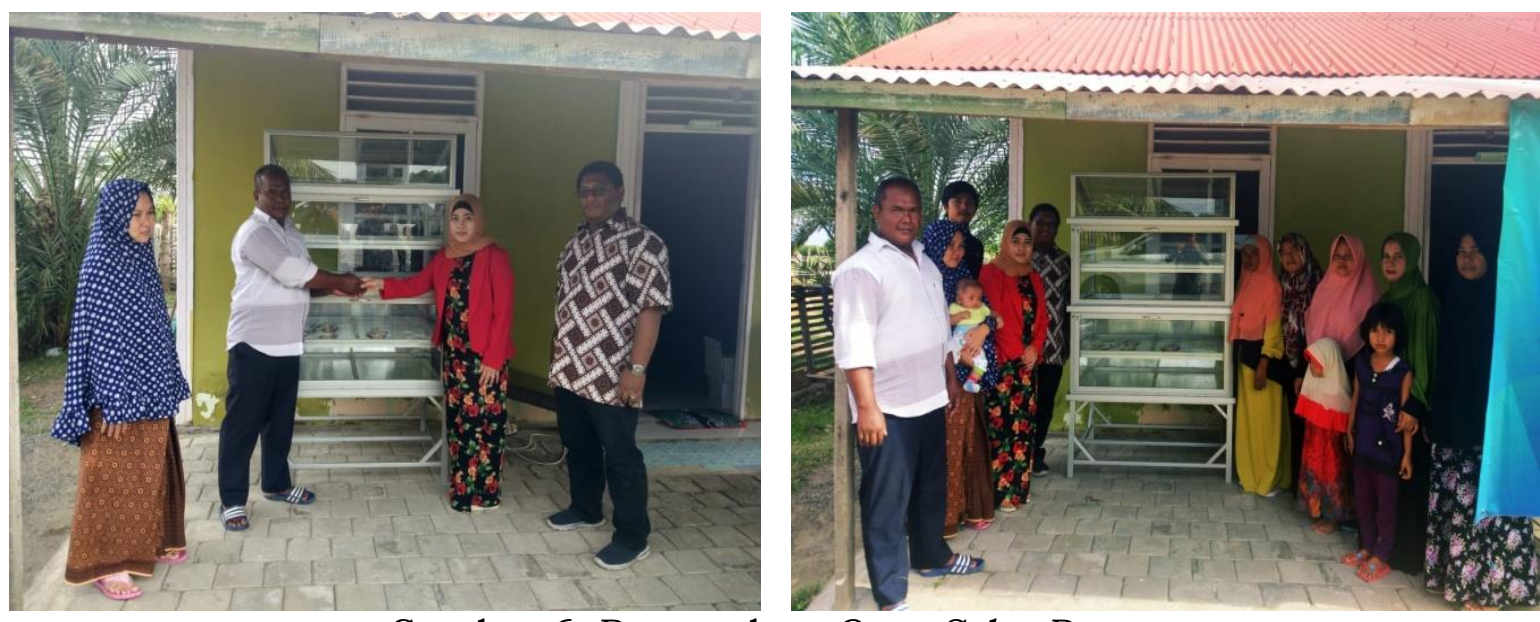

Gambar 6. Penyerahan Oven Solar Dryer

Upaya agar keberlanjutan produk dan keguanannya terus terjadi, dan untuk mengahadapi berbagai kendala yang mungkin muncul, untuk itu pihak pelaksana dengan masyarakat binaan terus melakukan komunikasi yang konstruktif sehingga tujuan dari PKM ini dalam membantu meningkatkan perekonomian masyarakat dapat terwujud.

\section{E. Keberhasilan Kegiatan}

Keberhasilan kegiatan ini dapat ditandai dengan terlaksananya program kemitraan masyarakat di Gampong Deah Raya tepat pada waktunya, dengan kehadiran dari ketua dan anggota kelompok, baik dari kelompok Usaha Engkut Taleung maupun dari kelompok Usaha Asen Belideung. Antusias dan keikutsertaan mereka dalam pelaksanaan PKM menunjukkan bahwa kegiatan PKM selesai dilaksanakan dengan baik dan berhasil. Terselesikannya pembuatan dan perakitan oven solar dryer juga menunjukkan kegiatan PKM ini berhasil, karena produk inilah yang akan digunakan dan diserahkan kepada masyarakat agar dapat dimanfaatkan sesuai dengan tujuan PKM.

Setelah oven selesai dirakit, maka selanjutnya dilaksanakan pelatihan pelatihan teknis agar masyarakat mengetahui manfaat dan fungsi serta teknik penggunaan oven, sebelum oven tersebut diserahkan kepada mereka. Penilaian pengetahuan dan keterampilan dilakukan pada saat pelatihan teknis penggunaan oven. Masyarakat diberi kesempatan untuk melakukan praktek langsung penggunaan oven setelah pelatihan dan demonsrasi selesai dilakukan oleh tim. Berdasarkan penilaian diketahui bahwa masyarakat telah dapat menggunakan oven untuk melakukan pengeringan ikan asin, melakukan bongkar pasang bagian oven untuk dapat dipindah tempatkan, serta telah dapat merawat dan membersihkan oven dengan baik dan benar. Dengan demikian maka dapa dikatakan bahwa kegiatan penyuluhan dan demontrasi tersebut dapat terselesaikan dengan baik dan berhasil. Di akhir kegiatan PKM dilakukan 
penyerahan unit oven solar dryer kepada masyarakat sebagai tanda bahwa kegiatan PKM ini telah berhasil dilaksanakan.

\section{Kesimpulan}

Hasil pelaksanaan program pengabdian kepada masyarakat pada pembuatan oven solar dryer untuk masyarakat nelayan dan pengusaha ikan asin di kota Banda Aceh, menunjukkan bahwa kedua keolompok masyarakat pengolah ikan asin sangat antusias dalam mengikuti seluruh kegiatan. Oven solar dryer sebagai teknologi pengolahan ikan asin dapat menjadi solusi terbaik dalam mengurangi pembusukan dan kerusakan ikan, serta dapat mengatasi kelebihan hasil tangkapan yang belum laku di pasarkan, dan menghasilkan produksi ikan asin yang lebih baik, sehingga dapat meningkatkan daya jual masyarakat nelayan di Aceh.

\section{Ucapan Terima Kasih}

Penulis mengucapkan terimakasih kepada Direktorat Jenderal Penguatan Riset Dan Pengembangan, RISTEKDIKTI yang telah memberi dukungan financial terhadap pengabdian kepada masyarakat.

\section{Referensi}

Afrianto, E., \& Liviawaty, E. (1994). Pengawetan dan pengolahan ikan. Kanisius: Yogyakarta.

Bintang, Y. M., Pongoh, J., \& Onibala, H. (2013). Konstruksi dan kapasitas alat pengering ikan tenaga surya sistem bongkar-pasang. Jurnal Media Teknoloi Hasil Perikanan, 1(2), 40-43.

Chavda, T. V., \& Kumar, N. (2009). Solar dryers for high value agro prodcuts at spreri. International Solar Food Processing Converence, 2009, pp. 1-5. Retrieved 14/9/19 from http://images3.wikia.nocookie.net/_cb57526 /solarcooking/images/9/97/Solar_Dryers_For_High_Value_Agro_Prodcuts_at SPRERI_- T.V. Chavda and Naveen Kumar_2009.pdf.

Deosthale, R. S., \& Kewat, S. (2018). Introduction of solar drying by NGO Narmada in Nimar region of Madhya Pradesh State of India under the guidance of Barc,goi. Consolfood, 22-23 \& 24th January, 2018, pp 1-6. Retrieved 14/9/19 from http://www.consolfood.org/wp-content/uploads/2018/02/L22_Abs\% 20Raghav.pdf.

Dewi, P. S., \& Widiyawati, I. (2019). Penerapan teknologi budidaya tanaman obat sebagai upaya pemanfaatan lahan pekarangan di Kelurahan Pabuwaran, Purwokerto, Jawa Tengah. Jurnal Panrita Abdi, 3(2), 105-112.

Hanafri, M. I., Emawan, A. H., Kustanti, E., \& Rahayu, E. L. (2009). Pembuatan prototipe alat solar dryer berbasis tenaga surya hybrid sistem portable. Retrieved 14/2/19 from http://directory.umm.ac.id/penelitian/PKMI/pdf/ PEMBUATAN\%20PROTOTIPE\%20ALAT\%20SOLAR\%20DRYER\%20BERBASIS \%20TENAGA\%20SURYA\%20HYBRID\%20SISTEM\%20PORTABLE.pdf.

Hubackova, A., Kucerova, I., Chrun, R., Chaloupkova, P., \& Banout, J. (2014). Development of solar drying model for selected cambodian fish species. Hindawi Publishing Corporation, The Scientific World Journal, Vol 2014, Article ID 439431, 10 pages, doi: http://dx.doi.org/10.1155/2014/439431.

Mudzanatun, Fajriyah, K., \& Muflihati, I. (2019). Aplikasi teknologi pangan dalam pengolahan potensi lokal umbi-umbian di Desa Tamanrejo Kecamatan Limbangan. Jurnal Panrita Abdi, 3(1), 18-31.

Mwamba, I., Tshimenga, K., Kayolo, J., Mulumba, L., Gitago, G., Tshibad, C. M., Noël, J., \& Kanyinda, M. (2017). Comparison of two drying methods of mango 
(oven and solar drying). MOJ Food Process Technol, 5(1), 240-243, doi: 10.15406/mojfpt.2017.05.00118.

Sanmartin, G., Buj, J., Marin, J., Cortes, L., Bossa, L., Puello, J. (2017). Design of an apparatus for solar drying of farm products. Chemical Engineering Transactions, 57, pp. 235-240, doi: 10.3303/CET1757040.

Situmeang, R. G., \& Hendrik, Z. (2017). Analisis usaha pengolahan ikan asin di Kelurahan Pondok Batu, Kecamatan Sorudik, Kota Sibolga, Provinsi Sumatera Utara. Jurnal Unri, 4(1), 1-9.

Penulis:

Herlina, Pendidikan Ekonomi, FKIP, Universitas Serambi Mekkah, Banda Aceh. E-mail: lalutaflower@gmail.com

Dian Aswita, Pendidikan Biologi, FKIP, Universitas Serambi Mekkah, Banda Aceh. E-mail: aswita_dian@yahoo.com

Ikramullah Zein, Teknik Industri, FT, Universitas Serambi Mekkah, Banda Aceh. E-mail: ikramullah.zein@serambimekkah.ac.id

Bagaimana men-sitasi artikel ini:

Herlina, H., Aswita, D., \& Zein, I. (2020). Oven Solar Dryer Teknologi sebagai upaya Peningkatan Produksi Ikan Asin pada Masyarakat Nelayan di Gampong Deah Raya kota Banda Aceh. Jurnal Panrita Abdi, 4(2), 255 - 264. 